\title{
Examining how students' knowledge of the subject domain affects their process of modeling in a computer programming environment
}

\author{
Marios Papaevripidou ${ }^{1}$ - Zacharias C. Zacharia ${ }^{1}$
}

Received: 21 January 2015/Revised: 13 March 2015/Accepted: 25 May 2015/

Published online: 10 June 2015

(C) Beijing Normal University 2015

\begin{abstract}
The purpose of this study was to investigate whether learners with different science content knowledge backgrounds, namely physics and science education graduates, construct models differently in the same computer programming environment with graphically represented program language and for the same subject matter (1D collisions). To do so, we selected 28 participants for each group and offered them the same modeling-based learning treatment. Data collection involved the administration of two paper-and-pencil tests, the participants' created models, and screen-capture data (both video and sound). The first test examined the participants' content knowledge on 1D collisions and the second one participants' modeling competence. The data analysis involved both qualitative and quantitative methods. The findings revealed that variation in science background knowledge appears to affect the learners' modeling competence, the types and nature of the models created, and the model creation progression followed.
\end{abstract}

Keywords Modeling-based learning · Modeling competence $\cdot$ Science background knowledge . Computer programming environment

\section{Introduction}

Modeling has been an integral part of the scientific enterprise from its origins, as experimentation and the broader enterprise of inquiry are profoundly situated in model building, testing, and revising (Duschl and Grandy 2008; Oh and Oh 2010).

Zacharias C. Zacharia

zach@ucy.ac.cy

Marios Papaevripidou

mpapa@ucy.ac.cy

1 Research in Science and Technology Education Group, Department of Educational Sciences, University of Cyprus, P. O. Box 20537, 1678 Nicosia, Cyprus 
Scientists create and use models (the products of modeling) to portray their current understanding of a system (or parts of a system) under study, to aid in the development of questions and explanations, and to communicate ideas in public (NRC 2012). Through modeling, scientists aim to test their ideas against observations in the real world and to assess the adequacy of their formulated models against standards of evidence (Hestenes 2010; Windschitl et al. 2008). In addition, models could also serve as tools for scientists' communication of their research findings within the scientific community (Nersessian 1992

Given the scientific value of modeling, science educators have argued in favor of using modeling for learning purposes (henceforth termed modeling-based learning), especially in the domain of physics (e.g., Hestenes 1987, 1992), as a way to provide students with new means for portraying their understandings, applying scientific practices/skills, and communicating their ideas. Models have a twofold nature. They can be both concrete (external models) and conceptual (internal models). For the purposes of this paper, we refer to external models, which are concretized through some sort of means/tools (e.g., paper-and-pencil, computer programming environments). Our view of external models complies with the theory of constructionism for an external model (Kafai and Resnick 1996; Papert 1980, 1993). In this theory, external models are considered representations of physical phenomena/systems and students learn in their quest to concretize these phenomena/systems through creating models. According to Louca and Zacharia (2014) learning occurs when students identify the components that comprise a phenomenon/system, namely its objects (e.g., a ball, a molecule), processes (e.g., movement of objects), entities (e.g., velocity), and interactions (e.g., how entities interact with objects or processes). Complete understanding of the phenomenon/system requires identifying all of these components and understanding the purpose each one of them serves. For example, the absence of the interactions component would translate to the absence of understanding of how the phenomenon/system functions (Louca and Zacharia 2008, 2014).

In addition to the construction of models, modeling-based learning also entails refining, revising, testing, evaluating, and validating scientific models (Hestenes 2010), as well as learning about the nature, purpose, and utility of scientific models (Bamberger and Davis 2013; Duschl et al. 2007; Schwarz and White 2005; Schwarz and Gwekwerere 2006; Windschitl et al. 2008). Modeling is a complex process that involves many constituent activities, and thus, it requires both specific practices and knowledge that need to be mastered by learners in order to respond effectively to the various challenges that scientific modeling entails. Based on previous research, we have identified a number of practices, as well as two types of knowledge that are essential for an individual to effectively and successfully engage with the scientific modeling process presented above. Specifically, the practices that appear to be involved in the scientific modeling process are model formulation (Duschl et al. 2007; Lehrer et al. 1994), model comparison (Penner et al. 1997; Pluta et al. 2011), model evaluation (Fretz et al. 2002; Pluta et al. 2011; Schwarz and White 2005), and model validation (Halloun 1996; Snir et al. 2003). The first type of knowledge that is important for a self-regulated learner engaged in the scientific modeling process concerns the explicit identification and description of the major steps of the 
scientific modeling process (termed metacognitive knowledge about the modeling process). The second type of knowledge that is important for the scientific modeling process is the epistemic knowledge or "meta-modeling knowledge" that corresponds to understanding of the nature of models and appreciation of the purpose and utility of scientific models (Schwarz and White 2005; Oh and Oh 2010). For the purposes of this study, we assumed that these three constituent components comprise students' modeling competence. We believe that it is not possible for an individual to successfully complete the scientific modeling process without mastering the aforementioned practices and knowledge.

Another important aspect for implementing modeling-based learning is the modeling tool itself. Extant research shows that the quality and functionality of a model depend on the tool used (Louca and Zacharia 2008; Papaevripidou et al. 2007). Consequently, an individual's modeling-based learning varies according to the modeling tool used. According to the literature, modeling can be enacted through various tools (Louca and Zacharia 2012), with computer-based tools appearing to be the most promising for modeling-based learning (Barab et al. 2001; Fretz et al. 2002; Louca and Zacharia 2008, 2012, 2014; Louca et al. 2011, 2012; Pata and Sarapuu 2006; Penner 2001). Their popularity is grounded in the unique capabilities they offer when used for modeling-based learning, such as allowing the creation and visualization of abstract objects and entities, and the creation of dynamic representations which permit observations similar to those observed in the real world (Sins et al. 2005). For the purposes of this study, we also decided to use a computer-based modeling tool, namely a computer-based programming environment.

\section{Computer programming environments as a means for modeling in science}

Prior research has well documented that computer-based programming environments (CPEs) can be used as modeling tools (e.g., Louca and Zacharia 2008, 2012, 2014; Louca et al. 2011, 2012; Sherin 2001; Sherin et al. 1993). In particular, the program language of the CPE can be used as the modeling medium. By using the program language an individual can write a program code that generates a model, namely a dynamic computer-based representation (animation or simulation like), that virtually animates/simulates the physical phenomenon/system under study. In this context, computer programming corresponds to modeling and the produced animation/simulation corresponds to the scientific model (Sherin 2001).

A large number of CPEs currently exist (e.g., Stagecast Creator, Microworlds EX). The most important criterion to consider when selecting a CPE for modeling purposes is the programming language that each CPE uses. Louca and Zacharia (2008) distinguish between textual program languages (Papert 1993) and graphical program languages (Singh and Chignell 1992). In the case of textual program languages, a specific written language is used for programming, whereas in the case of graphical program languages programming is done by demonstration, using "click-and-drag" techniques (Smith and Cypher 1999). Obviously, the latter programming method is the easier way to go, since it does not require the knowledge of a particular written source code. 
From an educator's perspective, the assessment of the status of a CPE model can be achieved in two ways. First, by observing the behavior of the model on the computer screen, the educator can quickly understand whether the constructed model accurately simulates the way the phenomenon/system operates in real life. This is also an indicator of what aspects of the phenomenon (i.e., objects, processes, entities, and interactions) the learner has understood. Obviously, this is the fastest way for an educator to see if a learner's modeling process is on the right track. On the other hand, such an assessment does not provide full insight to the learners' thinking. To do so, a second form of assessment should be used, namely, examination of the programming code that corresponds to this model. The programming code allows the educator to read the "story" behind the model. This "story" can reveal whether all of the phenomenon's objects, processes, entities, and interactions have been included in the model, as well as whether all the interconnections among these aspects are in place (Louca and Zacharia 2008, 2014).

\section{This study}

One of the major gaps in the modeling-based learning domain in science education relates to the effect of learners' background knowledge on their modeling process (Bamberger and Davis 2013; Louca and Zacharia 2012). Seeking to address this gap and to understand how learners with different science content background knowledge enact modeling in CPEs, we selected two groups of graduate students who differed in terms of their physics background and aimed to answer the following research questions:

1. Do graduate students with different physics content knowledge (physics vs. science education graduates) develop similar modeling competence after completing our study's modeling activity sequence and doing modeling in Stagecast Creator (a graphically represented program language CPE)?

2. Does the science content knowledge of graduate students (physics vs. science education graduates) affect their modeling process in Stagecast Creator (a graphically represented program language $\mathrm{CPE}$ )? If yes, how is this reflected in the models created?

\section{Methods}

\section{Participants}

The participants in the study were 56 graduate students ( 38 females, 18 males) with different physics background, enrolled in a science education Master's program. Specifically, 28 graduates had a bachelor's degree in physics (PhG) and 28 of them had a bachelor's degree in educational sciences with a specialization in science education $(\mathrm{SEdG})$. The courses that the two groups attended differed, primarily, in terms of the number of physics courses (in favor of $\mathrm{PhG}$ ) and the number of 
education course (in favor of the SEdG). One PhG student had a second bachelor degree in education and two other PhG students a minor in education. It should be noted that there were no types of courses (e.g., psychology, research methods, science, education) that both groups did not attend at least one either during their undergraduate or their graduate studies. The science education courses attended by the SEdG students included at least four content-oriented science courses (the majority was physics), whereas, the PhG students attended more than 20 physics courses.

The two groups of students were selected from a larger pool of individuals (68 in total; randomly selected) who attended a master's course on the use of new computer technologies in science education, when pursuing a Master's degree in Science Education. Not all participants attended the course at the same time (the data were collected from four different semesters). However, all aspects related to the course were the same (e.g., curriculum, instructors, time-on-task, computer labs) no matter which semester the course was offered. Additionally, to ensure that no differences existed among the members of the two groups in terms of their initial modeling competence, we used the pretest data, which revealed no statistical significant differences either between or within the two groups (see the "Results" section below). The latter procedure also enabled us to narrow down the number of possible participants according to the homogeneity of their pretest scores. Students that were found to have pretest scores greater or lower than the mean score plus or minus two $S D$ the most, respectively, were excluded (12 in total; 7 from the SEdG and 5 from the $\mathrm{PhG}$ conditions). Finally, students within each condition (PhG and SEdG) were randomly assigned to subgroups of two. They worked in dyads throughout this study. PhG students worked only with another PhG students and SEdG only with SEdG students in two adjacent computer labs (each condition was assigned to a separate lab). The two conditions did not interact with each other at any point of the study.

\section{Context of the study}

The master's course on the use of new computer technologies in science education was devoted to computer-based modeling (in all thirteen 3-h sessions). In particular, we engaged students in the process of creating models through the use of a computer-based modeling tool in the context of 1-D elastic collisions. We selected 1-D elastic collisions as a subject matter domain because we wanted a topic that the SEdG students did not know well (none of them were taught this topic at the college level) and that could be easily modeled with our study's computer-based modeling tool (it required only one track and two masses colliding; we did not want our participants to be distracted with design/appearance issues or to attempt to model a complex phenomenon with many objects, processes, entities, and interactions).

As a computer-based modeling tool we selected a graphically represented program language CPE, namely Stagecast Creator. All participants completed three 3-h training sessions for learning how to use Stagecast Creator to create models through programming. Below, we provide details about Stagecast Creator, the curriculum (modeling activity sequence) involved and the procedures followed. 


\section{The computer-supported modeling tool}

Stagecast Creator (SC) was selected because of its ease of use and its effectiveness as a modeling tool (Louca and Zacharia 2008, 2014; Louca et al. 2012; Papaevripidou et al. 2007). SC falls under the umbrella of graphically represented program language CPEs. This means that the user can program by demonstration and visual before-after rules. In this way, no syntactic programming language is needed (Smith et al. 2000). To create a model in SC you need to add objects (e.g., a cart) and entities (e.g., vectors) to the modeling space and then assign rules to these objects and entities in an attempt to define processes and interactions. A rule can be added after the user presses the create-a-rule button and then selects the object or entity being programmed. Immediately, the Rule Maker window opens with the object or entity shown in its current state. The user then enacts the behavior s/he wishes to set for this object or entity, for example, by dragging the character to a new position on the modeling space. Figure 1 shows a created rule in SC.

Variables are another important characteristic of programming in SC. A variable in $\mathrm{SC}$ is useful when it is incorporated in the creation of a rule either in association with or to control a specific action of an object. In the example in Fig. 1, the user has used a variable for the cart character, which she labeled as "velocity." In

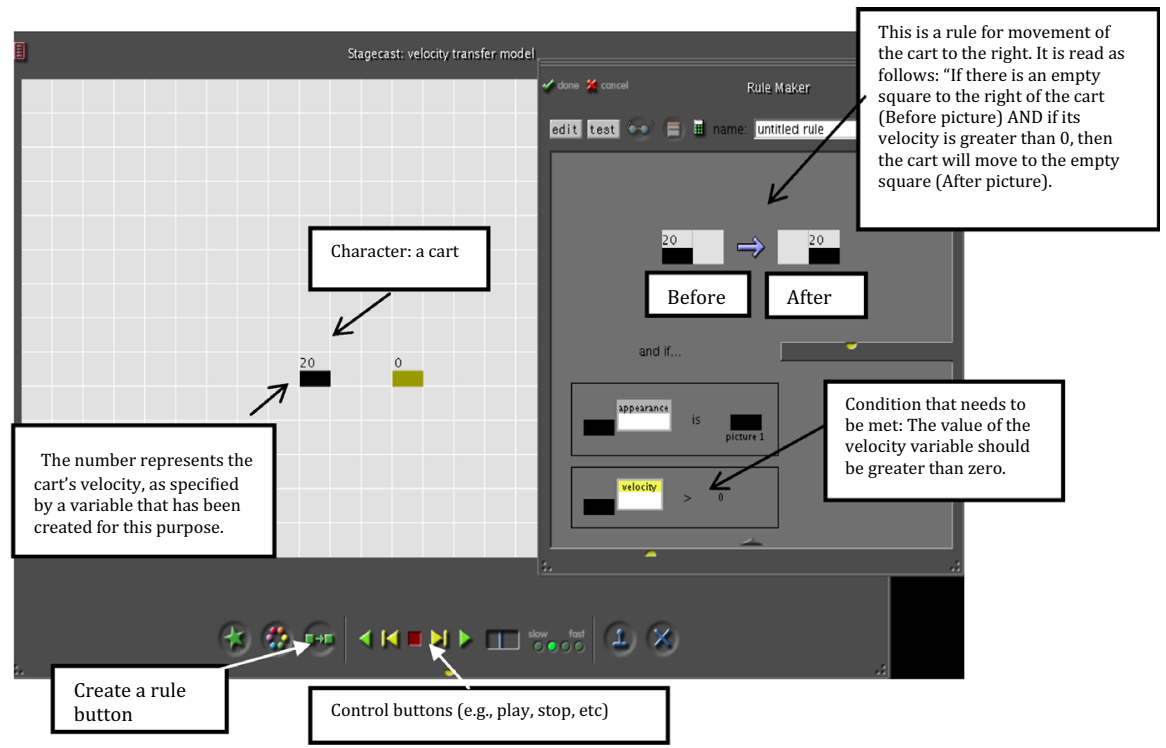

Fig. 1 A move to the right rule for a cart character in Stagecast Creator. To execute the rule in Fig. 1, the user presses the "play" button. This rule will continue to be executed until the presupposition "if there is an empty square to the right" is violated (e.g., if the cart character encounters another character to its right). In this case, the program searches for another rule that matches the current conditions in order to set the character's behavior 
creating the move-to-the-right rule, she specified that this character would move one square to the right, if its velocity value is greater than zero.

\section{The context and structure of the modeling activities}

The participants had to study a set of five 1-D collision phenomena (see Table 1 for further details) and create models, first on paper and then using SC, but without a fixed sequence of activities for the students to follow. Every time students were prompted to create a model for an observed class of collision, they were only asked to make sure that their model fulfilled three important criteria; to (i) represent what the phenomenon looks like (i.e., inclusion of objects and entities), (ii) illustrate the mechanism their model was built on that accounted for how the phenomenon functioned (i.e., inclusion of processes and interactions), and (iii) use their model for formulating and testing predictions for new situations of 1-D collisions. To monitor students' modeling progress, the instructors paid close attention to students' talk during planning and developing their models in their dyads, and constantly assessed their thinking through conversations. Additionally, students' ongoing reflections were also captured in an online learning platform in which the students were asked each time to upload their final models, provide a description of the steps followed for creating their models, and evaluate their models with respect to the three given criteria.

To facilitate interaction and productive talk among the student dyads, the instructors grouped specific dyads together and asked them to use the asynchronous chat tool of the online platform to evaluate their matched dyad's models and post comments, questions, and suggestions for further improving their models. The grouping of the dyads was done on a random basis and dyads were only matched with others in the same condition.

The different classes of collision phenomena that students were expected to observe and then model were videorecorded prior to the study and were then embedded in the Coach 6 computer learning environment (Heck et al. 2009), which enables making measurements and doing data analysis on video clips. Each video file followed a collision experiment from beginning to end, and the velocity of each cart was measured and displayed in tables and on graphs on the software environment. The five classes of collision, in conjunction with an overview of the modeling activities that were implemented for the purposes of this study, are presented in Table 1.

\section{Procedures}

The study was conducted in four consecutive phases and lasted throughout an academic semester (thirteen 3 -h sessions, one session per week). Phase 1 and Phase 4 entailed the assessment of students' content knowledge and modeling competence, whereas Phase 2 was devoted to enabling students to familiarize themselves with SC and Phase 3 was devoted to using the SC for constructing, revising, and testing models for a sequence of 1-D collision phenomena. 
Table 1 The activity sequence followed for each of the five classes of collision

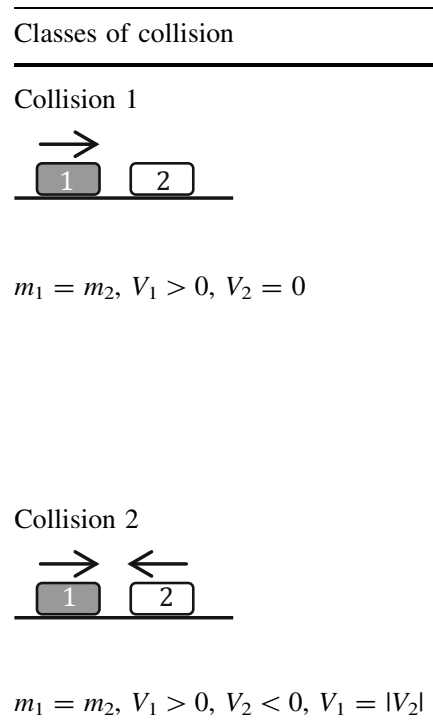

\section{Collision 3}

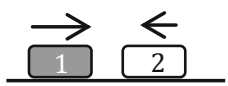

$m_{1}=m_{2}, V_{1}>0, V_{2}<0, V_{1}>\left|V_{2}\right|$
Description of the activity sequence

1. Observe a perfectly elastic collision of two carts (Collision 1)

2. Create a graphical representation on paper (paper-and-pencil model) to illustrate how the collision phenomenon occurs

3. Decide on a plan for how to create a model in SC based on the paper-and-pencil model

4. Create the SC model (model 1)

5. Upload the final SC model in the online learning platform. Describe the mechanism that was created for controlling the behavior of each cart prior to, during, and after the collision

6. Comment on, evaluate, and pose questions about another dyad's model

1. Observe a perfectly elastic collision of two carts (Collision 2)

2. Test whether model 1 applies for the second class of collision. If it applies, students proceed to Collision 3

3. If it does not apply, students proceed to create a new graphical representation on paper (paper-and-pencil model) to illustrate how the collision phenomenon occurs

4. Decide on a plan for how to create a model in SC based on the paper-and-pencil model

5. Create the SC model (model 2)

6. Test whether model 2 applies for Collision 1 and make an evaluation report

7. Upload the final SC model in the online learning platform. Describe the mechanism that was created for controlling the behavior of each cart prior to, during, and after the collision

8. Comment on, evaluate, and pose questions about another dyad's model

1. Observe a perfectly elastic collision of two carts (Collision 3)

2. Test whether models 1 and 2 apply for the third class of collision. If either of them applies, students proceed to Collision 4

3. If neither applies, students proceed to create a new graphical representation on paper (paper-and-pencil model) to illustrate how the collision phenomenon occurs

4. Decide on a plan for how to create a model in SC based on the paper-and-pencil model

5. Create the SC model (model 3)

6. Test whether model 3 applies for Collisions 1 and 2 and make an evaluation report

7. Upload the final SC model in the online learning platform. Describe the mechanism that was created for controlling the behavior of each cart prior to, during, and after the collision

8. Comment on, evaluate, and pose questions about another dyad's model 
Table 1 continued

\begin{tabular}{ll}
\hline Classes of collision & Description of the activity sequence \\
\hline Collision 4 & 1. Observe a perfectly elastic collision of two carts (Collision 4) \\
$\rightarrow+$ & 2. Test whether models 1, 2, and 3 apply for the fourth class of \\
& collision. If any of them apply, students proceed to Collision \\
\hline
\end{tabular}

$m_{1}=m_{2}, V_{1}, V_{2}>0, V_{1}>V_{2}$

3. If none apply, students proceed to create a new graphical representation on paper (paper-and-pencil model) to illustrate how the collision phenomenon occurs

4. Decide on a plan for how to create a model in SC based on the paper-and-pencil model

5. Create the SC model (model 4)

6. Test whether model 4 applies for Collisions 1, 2, and 3 and make an evaluation report

7. Upload the final SC model in the online learning platform. Describe the mechanism that was created for controlling the behavior of each cart prior to, during, and after the collision

8. Comment on, evaluate, and pose questions about another dyad's model

Collision 5

1. Observe a perfectly elastic collision of two carts (Collision 5)

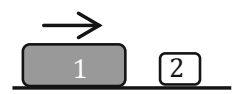

2. Test whether models $1,2,3$, and 4 apply for the fifth class of collision. If any of them apply, students are finished with constructing models

$m_{1}=2 m_{2}, V_{1}>0 V_{2}=0$

3. If none apply, students proceed to create a new graphical representation on paper (paper-and-pencil model) to illustrate how the collision phenomenon occurs

4. Scaffold-Students are prompted to calculate the product of mass and velocity of each cart in Collision 5. Then they calculate the sum of the products prior to and after collision, and conclude that the sums are equivalent. At this point they are introduced in the conservation of momentum law

5. Decide on a plan for how to create a model in SC based on the paper-and-pencil model

6. Create the SC model (model 5)

7. Test whether model 5 applies for Collisions 1, 2, 3, and 4 and make an evaluation report

8. Upload the final SC model in the online learning platform. Describe the mechanism that was created for controlling the behavior of each cart prior to, during, and after the collision

9. Comment on, evaluate, and pose questions about another dyad's model

\section{Phase 1 (duration: one 3-h session)}

At the beginning of the course, tests on content knowledge and modeling were administered to assess students' prior content knowledge about 1-D elastic collision phenomena and their modeling competence, respectively (see "Data collection" section for further details). These two types of tests were administered at the 
beginning of the course so that the analysis of the data collected would enable the formation of dyads of students with the same conceptual understanding and modeling competence background while working with the modeling activities in Phase 3 (see below). The latter was done because we aimed to monitor how students with the same background knowledge would develop conceptual understanding and modeling competence as a result of their participation in the modeling activities of Phase 3.

\section{Phase 2 (duration: three 3-h sessions)}

Based on students' performance on the conceptual and the modeling competence tests, 28 dyads with similar conceptual understanding and modeling competence background were formed and maintained for the rest of the study. Each dyad accessed a computer at the physics lab, first to familiarize themselves with SC using the software tutorial, and then to use a specially designed curriculum through which they were expected to develop programming competence on how to (i) formulate simple and complex rules and programs, (ii) create and integrate variables into rules and programs, and (iii) debug rules and programs. The context of this curriculum did not relate to the context of the modeling activities that were implemented in Phase 3.

\section{Phase 3 (duration: eight 3-h sessions)}

At the beginning of Phase 3, the students were asked to maintain the dyads they had worked with during Phase 2 and were informed that, for the next eight sessions, they would use the SC for developing models for a set of five collision phenomena. The collision phenomena were stored in separate video files on each dyad's computer. They were added sequentially to the Coach 6 computer learning environment as each dyad of students finished developing and revising a model that corresponded to the current collision phenomenon. Coach 6 was presented through a whole-class demonstration and a step-by-step guide was followed to help students familiarize themselves with the video analysis tool and the data measurement function.

In the beginning of the first session of Phase 3, the instructors briefly overviewed how students were expected to model the elastic collision phenomena. They began by explaining the purpose of the course (e.g., we seek to create a model of elastic collisions that applies to a range of collision phenomena) and then described the steps that would be followed in accomplishing this task. These steps were openended in nature and involved observing the physical phenomenon (e.g., a video recording of a perfectly elastic collision of two carts), creating a graphical representation on paper (paper-and-pencil model) to illustrate how the collision phenomenon occurs, deciding on a plan for how to create a model in SC based on the paper-and-pencil model, and finally creating the model in SC. In creating their models in SC, the students were expected to design the characters that would represent each cart and were free to create the rules and variables through which the motion of the carts would be controlled. Programming in SC was the most demanding task for students, since it involved a considerable number of 
programming actions, such as creating, editing, testing, and debugging rules and programs, creating, defining, and integrating variables into rules and programs. From a modeling perspective, the aforementioned steps, in conjunction with the programming actions that students completed, provided students with fruitful learning experiences since they were "implicitly" involved in multiple and iterative cycles of model development and deployment in the context of elastic collisions. In addition, students' modeling experiences were enhanced by using the online learning platform for the purposes of comparing their peers' models with their own and providing evaluation feedback to each other. The feedback received served as a means for revisiting their models in order to further improve or revise them. Thus, the new models became more robust in terms of their representational complexity (e.g., elements of the model, objects, entities, processes, and interactions, were represented in a more comprehensive manner), their interpretive potential (e.g., the model provided an improved mechanism that helped to illustrate how and why the phenomenon functioned the way it did), and their predictive power (e.g., the revised model better enabled the formulation and testing of predictions for instances other than those observed).

The time spent on each collision case varied across the dyads, based on the modeling procedure, the mode of programming, and the type of feedback received from their peers (from the same condition).

\section{Phase 4 (duration: one 3-h session)}

During the last course session, the content knowledge and modeling competence tests were administered again to the participants as posttests, this time in order to assess whether students' knowledge about 1-D elastic collisions and their modeling competence were enhanced as a result of their participation to the modeling activities of the course, and whether there were any observable differences related to initial level of background knowledge.

\section{Data collection}

Data were collected from several data sources. First, we developed and used two paper-and-pencil tests, namely a content knowledge and a modeling competence test. The knowledge test was administered to assess students' understanding of concepts concerning 1-D elastic collisions (e.g., kinetic energy, energy conservation, momentum conservation), both before and after the study. It included 5 openended items that asked conceptual questions, all of which required explanations of reasoning. All items consisted of several sub-items (each sub-item corresponded to one question). A representative example of a knowledge assessment item (made up of 3 sub-items) appears in Appendix (Table 7).

To ensure valid and reliable scores for this knowledge test, we followed validity and reliability checks. Specifically, the test was checked in terms of face and content validity (both were deemed sufficient by a panel of experts), as well as for reliability. For the latter, Cronbach's alphas were calculated for each of the test's 
items with a larger sample (different from the one in this study, but from the same population) prior to this study. All alpha measures ranged from 0.73 to 0.81 .

The modeling competence test was used to assess students' (i) modeling practices (e.g., model construction, model evaluation, comparing and contrasting models of the same phenomenon, model validation), (ii) metacognitive knowledge about the modeling process, and (iii) meta-modeling knowledge with respect to the nature and purpose of models, both before and after the study. It included fourteen open-ended items, two for each component of modeling competence. Each pair of items that pertained to the same modeling competence component was isomorphic in format but each was based on a different context. Many of these items consisted of several sub-items (each sub-item corresponded to one question). The context of the items differed from the context of elastic collisions that was used during students' modeling practice in Phase 3. The context for the fourteen modeling competence test items appears in Table 2 and a representative example of the item used to assess the practice of model construction appears in Appendix (Table 8). The validity and reliability of the scores on this test were also checked. We checked face and content validity (both were deemed sufficient by a panel of experts), as well as for reliability. For the latter, Cronbach's alphas were calculated for each of the test's items with a larger sample (different from the one of this study, but from the same population) prior to this study. All alpha measures ranged from 0.77 to 0.86 .

In addition to the two tests, we used as data sources each dyad's (i) SC programming code when constructing models, (ii) asynchronous chat logs created in the online learning platform when exchanging models for evaluation/feedback purposes, (iii) the actual SC models created throughout the study, and (d) screencapture data, which included the discourse within each dyad, conversations with the

Table 2 Modeling competence test items

\begin{tabular}{ll}
\hline Component of modeling competence & Context of the items \\
\hline $\begin{array}{l}\text { I. Modeling practices } \\
\text { Model construction }\end{array}$ & A1. Horizontal projectile and free fall \\
A2. Cubic expansion & B1. Seeds growth model \\
Model revision & B2. Spinning wheel motion model \\
Models comparison & C1. Simple electric circuit models \\
Model validation & C2. Substance dilution models \\
II. Metacognitive knowledge about the modeling process & D1. Light refraction model \\
& D2. Sinking and floating model \\
E1. Water cycle \\
Nature of models & E2. Plant growth \\
& F1. Color vision \\
Purpose or utility of models & F2. Cell division \\
& G1. Respiratory system \\
\end{tabular}


course instructors, and actions performed on screen while using SC. For the last we used RiverPast ${ }^{\circledR}$ software, which allows the recording of both the actions performed by the user on the computer screen and the sounds occurring close to the computer.

\section{Data analysis}

Both the knowledge and modeling competence tests were scored and coded blind to participant condition. We took the individual student as the unit of analysis. The scoring of each sub-item of both tests involved the use of a scoring rubric that included preset criteria, which were used to score whether the elements of the participant's overall response (answer and its accompanying reasoning) were correct (for a sample of a scoring rubric see Appendix Table 9). The maximum score for each sub-item varied according to the number of prespecified elements required to be present. However, the maximum score for an item (the sum of the maximum scores of its sub-items) did not vary significantly across the items on a test. An individual's total score on a test was derived by adding all the assigned subitem scores, those for answers and for explanations and reasoning, and by adjusting the total to fit on a 100-point scale. An independent coder reviewed about $20 \%$ of the data. The reliability measures (Cohen's kappa) for scoring of the knowledge test and modeling competence test were .92 , and .90 , respectively.

The quantitative analysis involved independent samples $t$ tests for comparing the pretest scores for the two conditions on each test, paired samples $t$ tests for comparing the pretest-posttest scores for each condition for both tests, one-way ANCOVAs for comparing the posttest scores for the two conditions on the modeling competence test overall, as well as for each of the modeling competence components (see Table 2) separately (students' scores in the corresponding pretests were used as the covariate), and an independent samples $t$ test for comparing the gain scores (posttest scores minus the pretest scores) for the two conditions on the knowledge test. ${ }^{1}$

Students' responses in the modeling competence test were also treated qualitatively with the use of open coding techniques (Strauss and Corbin 1990). For each pair of the isomorphic items all participants' responses were read one by one and clustered into categories according to the reasoning and the elements of each response. Then the categories were refined and put in hierarchical order, starting with the ones that were far from the anticipated type of reasoning. From clustering of the response categories, a hierarchy of different levels emerged that illuminated the increasing sophistication that existed among students in terms of each component of their modeling competence. Finally, the prevalence for each one of the resulting levels for each modeling competence component was calculated. The purpose of the latter was to compare if the prevalence of each level of participants' ideas differed prior to and after the study and whether the developed modeling competence of the two groups of students was similar or differed.

\footnotetext{
1 We used gain scores because the two groups differed in terms of their background knowledge of Physics. We expected to find differences between the two groups on the knowledge pretest. This hypothesis was confirmed during our data analysis of the knowledge pretest (see the "Results" section).
} 
In addition to the analysis of the two tests, we analyzed the participants' Stagecast models qualitatively. This analysis followed the procedures of artifact analysis adapted from a different study (Louca et al. 2011). Codes from this analysis involved the nature of mechanisms that students chose to incorporate in their models, the elements used for representing their models (e.g., objects, entities, processes, and interactions), as well as models' applicability to other classes of collisions and predictive power. To triangulate findings, we also analyzed student discourse derived from (i) the asynchronous chat logs created in the online learning platform while exchanging their models with their peers for evaluation/feedback purposes and (ii) from the screen-capture data, which included the discourse each dyad, conversations with the course instructors, and actions performed on screen while using SC to create, revise, test, and debug models. The focus during the discourse analysis was on the students' planning and thinking during creating, testing, and evaluating their models. For internal consistency reliability purposes, a second independent rater reviewed about $20 \%$ of the data. The reliability measures (Cohen's kappa) for classifying students' models using the emerged codes was 0.88 .

\section{Results}

\section{Research question 1}

The paired samples $t$ test showed that both conditions improved students' knowledge about 1-D elastic collisions and modeling competence $(p<0.0001$ and $t \gg 1$ for all comparisons).

The independent samples $t$ test indicated that the conditions did not differ in pretest scores on the modeling competence test, both overall and for each of the modeling components, $t<1$, $n s$ (for means and standard deviations see Table 3 ). On the other hand, statistically significant differences were found between the two conditions in scores on the knowledge pretest, $t(54)=66.7, p<0.001$ $\left(M_{\mathrm{SEdG}}=12.9, S D_{\mathrm{SEdG}}=3.0\right.$ and $\left.M_{\mathrm{PhG}}=76.3, S D_{\mathrm{PhG}}=3.9\right)$.

An ANCOVA was done for students' scores on each of the components of the modeling competence posttest, as well as for students' overall scores on the modeling competence posttest, with pretest scores as covariates and condition as between-subjects factor. The ANCOVA revealed a main effect of condition on Metacognitive knowledge about the modeling process and Meta-modeling knowledge (Nature of models and Purpose or utility of models), as well as for the modeling practices (Model revision, Models comparison, and Model validation), with the exception of model construction (for the ANCOVA results, see Table 4). The mean scores of the SEdG students were higher than those of the PhG students (for the means and standard deviations see Table 3). An ANCOVA done on the overall scores on the modeling competence test also showed that the SEdG students had significantly higher posttest scores than the PhG students. These findings suggest that the difference in science (physics) background knowledge appears to cause statistically significant differences between the two conditions in terms of their modeling competence. 
Table 3 Mean scores and SD on each component of the modeling competence test for both conditions

\begin{tabular}{|c|c|c|c|c|}
\hline \multirow[t]{2}{*}{ Component of the modeling competence } & \multicolumn{2}{|c|}{ SEdG condition } & \multicolumn{2}{|c|}{ PhG condition } \\
\hline & $\begin{array}{l}\operatorname{Pre}^{\mathrm{a}} \\
\mathrm{M}^{\mathrm{b}}(S D)\end{array}$ & $\begin{array}{l}\text { Post }^{\mathrm{a}} \\
\mathrm{M}^{\mathrm{b}}(S D)\end{array}$ & $\begin{array}{l}\text { Pre } \\
\mathrm{M}^{\mathrm{b}}(S D)\end{array}$ & $\begin{array}{l}\text { Post } \\
\mathrm{M}^{\mathrm{b}}(S D)\end{array}$ \\
\hline \multicolumn{5}{|l|}{ I. Modeling practices } \\
\hline Model construction & $15.8(2.9)$ & $66.1(4.0)$ & $16.5(3.1)$ & $64.9(3.8)$ \\
\hline Model revision & $28.2(5.4)$ & $76.0(3.9)$ & $27.5(4.9)$ & $56.7(4.2)$ \\
\hline Models comparison & $10.9(3.2)$ & $86.5(3.8)$ & $9.4(2.8)$ & $61.9(3.4)$ \\
\hline Model validation & $5.6(2.8)$ & $65.3(4.0)$ & $5.1(2.5)$ & $45.7(4.1)$ \\
\hline $\begin{array}{l}\text { II. Metacognitive knowledge about the modeling } \\
\text { process }\end{array}$ & $16.2(7.1)$ & $80.7(3.9)$ & $15.7(6.4)$ & $56.4(3.7)$ \\
\hline \multicolumn{5}{|l|}{ III. Meta-modeling knowledge } \\
\hline Nature of models & $7.7(3.8)$ & $77.2(5.2)$ & $6.8(3.9)$ & $37.9(6.9)$ \\
\hline Purpose or utility of models & $9.7(5.4)$ & $79.8(3.4)$ & $10.8(4.8)$ & $46.2(4.3)$ \\
\hline $\begin{array}{l}\text { The modeling competence test as a whole (sum of all } \\
\text { components) }\end{array}$ & $13.5(3.9)$ & $75.9(3.8)$ & $13.1(3.5)$ & $52.9(2.9)$ \\
\hline
\end{tabular}

${ }^{\mathrm{a}}$ The pretest and posttest versions of the test were identical

b Scores were adjusted to a 100-point scale

Table 4 One-Way ANCOVA results and effect sizes across the components of the modeling competence test

\begin{tabular}{lcccc}
\hline Component of the modeling competence & $F$ & $d f$ & $p$ & $\begin{array}{l}\text { Effect size } \\
\text { (partial eta square) }\end{array}$ \\
\hline $\begin{array}{l}\text { I. Modeling practices } \\
\text { Model construction }\end{array}$ & 0.25 & 1,53 & 0.61 & 0.005 \\
$\quad$ Model revision & 337.7 & 1,53 & $>0.0001$ & 0.864 \\
$\quad$ Models comparison & 747.8 & 1,53 & $>0.0001$ & 0.934 \\
$\quad$ Model validation & 446.2 & 1,53 & $>0.0001$ & 0.894 \\
$\begin{array}{l}\text { II. Metacognitive knowledge about the } \\
\text { modeling process }\end{array}$ & 747.7 & 1,53 & $>0.0001$ & 0.934 \\
$\begin{array}{l}\text { III. Meta-modeling knowledge } \\
\text { Nature of models }\end{array}$ & 582.4 & 1,53 & $>0.0001$ & 0.917 \\
$\begin{array}{l}\text { Purpose or utility of models } \\
\text { The modeling competence test as a } \\
\text { whole (sum of all components) }\end{array}$ & 1322.8 & 1,53 & $>0.0001$ & 0.961 \\
\hline
\end{tabular}

An independent samples $t$ test was done for students' gain scores on the knowledge test. It was found that the gain scores of the two conditions differed significantly. Specifically, the mean gain score of the SEdG students was higher than that of the PhG students, $t(54)=46.7, p<0.001 \quad\left(M_{\mathrm{SEdG}}=53.8\right.$, $S D_{\mathrm{SEdG}}=3.1$ and $M_{\mathrm{PhG}}=15.7, S D_{\mathrm{PhG}}=2.9$ ). It should be noted, though, that the $\mathrm{PhG}$ students entered the study with high pretest scores (they had a strong physics background, including 1-D collisions) and that the mean scores on their 
Table 5 Most prevalent levels for each group of students and typical responses on the item that assessed students' model comparison practice (posttest)

\begin{tabular}{|c|c|c|}
\hline Levels & Level description & Example of a participant response \\
\hline $\begin{array}{l}\text { Level } 3 \text {-most } \\
\text { prevalent level } \\
\text { for PhG students }\end{array}$ & $\begin{array}{l}\text { Detection of the best or worst model } \\
\text { based on model's interpretive } \\
\text { potential }\end{array}$ & $\begin{array}{l}\text { "The Stagecast Creator model is the } \\
\text { worst model for describing and } \\
\text { explaining what is happening in the } \\
\text { electric circuit, because it doesn't } \\
\text { explain how or why the light bulb is lit } \\
\text { when the switch is on" [PhG\#52- } \\
\text { posttest] }\end{array}$ \\
\hline $\begin{array}{l}\text { Level } 5 \text {-most } \\
\text { prevalent level } \\
\text { for SEdG } \\
\text { students }\end{array}$ & $\begin{array}{l}\text { Detection of the best or worst model } \\
\text { based on model's } \\
\text { (i) representational } \\
\text { comprehensiveness, (ii)interpretive } \\
\text { potential, and (iii) predictive power }\end{array}$ & $\begin{array}{l}\text { "The best way to explain how the electric } \\
\text { circuit functions is the verbal } \\
\text { description because: } \\
\text { 1. It encompasses the basic components } \\
\text { of the phenomenon, e.g., light bulb, the } \\
\text { wires, the battery, type of circuit; open } \\
\text { or closed, status of brightness; no } \\
\text { brightness or normal brightness, the } \\
\text { connection of the light bulb to the } \\
\text { battery with the use of wires, the light } \\
\text { bulb interacts with the battery in order } \\
\text { to light } \\
\text { 2. It provides a mechanism that serves as } \\
\text { an explanation of the way the } \\
\text { phenomenon occurs, } \\
\text { 3. It enables the testing of predictions } \\
\text { because there is a description of how } \\
\text { the light bulb should be connected with } \\
\text { the battery with the use of wires and } \\
\text { thus we can formulate and then test a } \\
\text { prediction if the several parts of the } \\
\text { circuit are connected in a different } \\
\text { way" [SEdG\#2-posttest] }\end{array}$ \\
\hline
\end{tabular}

knowledge pretests and posttests were both higher than the SEdG students' mean score on the knowledge posttest.

The discrepancies found between the $\mathrm{PhG}$ and the SEdG students in terms of their modeling competence were also verified by the qualitative analysis of the data collected. For every aspect of their modeling competence, besides the model construction practice where no significant difference was found, the majority of the $\mathrm{PhG}$ students were classified at more inferior levels compared to the mostly superior levels at which the SEdG students were classified. Table 5 provides a representative example of the most prevalent levels that emerged for each group of students on an item that was used to assess their model evaluation practice. 


\section{Research question 2}

Students' SC models artifact analysis, in conjunction with the discourse analysis of their model evaluation and feedback chat logs, and the verbal interactions while creating their SC models during the course, revealed that students' attempts to create models in SC to represent the five different classes of collisions resulted in six different collision models and six different collision models progressions (see Table 6). Each of the six different models is described below, followed by the presentation of the six different collision models progression.

\section{Velocity "transfer" model}

The programming in this model was based on the idea of transferring the value of the velocity of the moving cart to the stationary one. The students who created this kind of model created a velocity variable for each of the two carts, a motion rule that controls the motion of each cart (e.g., "if the velocity of the cart is greater than zero, then move the cart one square to the right"), and in the event of a collision created a version of the following rule: "If the two carts appear at adjacent boxes, then copy the value of the velocity of the moving cart to the value of the velocity of the stationary cart, and then set the value of the velocity of the initial moving cart to zero." In the event of a collision this rule would be executed; the initial moving cart would become stationary and the stationary one would move to the right having acquired the velocity of the initial moving cart. This model applies only in the case of Collision 1 (a moving cart hits a stationary cart), but it works with any positive values for the velocity of the moving cart.

\section{Velocity "reflect" model}

This model applies to the case of two colliding carts moving in opposite directions with equal velocities. The mechanism that is behind the programming of this model was built on the idea that in the event of a collision the velocity of each cart will reverse its original "sign." The creators of this kind of model created a velocity variable for each of the two carts, two motion rules that control the motion of each cart (e.g., "if the velocity of the cart is greater than zero, then move the cart one square to the right," and "if the velocity of the cart is smaller than zero, then move the cart one square to the left"), and in the event of the collision created a rule that is a version of the following: "If the two carts appear at adjacent boxes, then change the sign of the value of the velocity of the left cart from positive to negative AND change the sign of the value of the velocity of the right cart from negative to positive." This model applies only in the case of Collision 2 (two carts with equal velocities moving toward each other), and it also applies to any collision similar to Collision 2 (the carts' velocities should be equal in value but opposite in sign). 


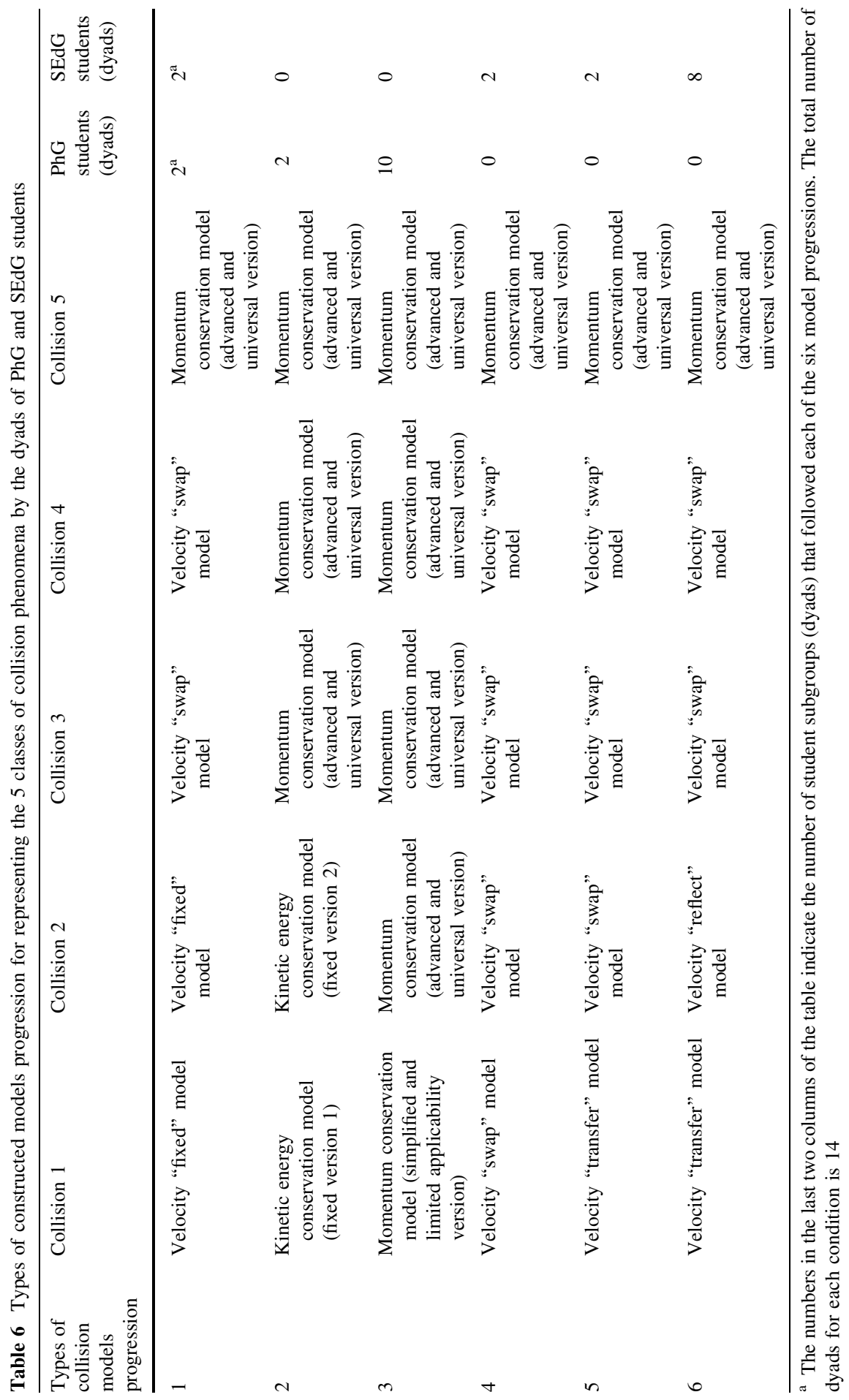


Velocity “swap” model

This model builds on the idea that two carts with equal mass will interchange (swap) their velocities at the event of the elastic collision. The programming behind this model entails basic programming steps similar to the previous models (e.g., creation of velocity variables for each cart, and two motion rules that control the motion of each cart, e.g., "if the velocity of the cart is greater than zero, then move the cart one square to the right," and "if the velocity of the cart is smaller than zero, then move the cart one square to the left"), and also the creation of two "after the collision" velocities, one for each cart. These variables are embedded in a programming rule that reads as follows: "If the two carts appear at adjacent boxes, then copy the velocity value of the left cart and put it in the 'after collision velocity' of the left cart, AND copy the velocity value of the right cart and put it in the 'after collision velocity' of the right cart, AND put the value of the 'after collision velocity' of left cart to the value of the velocity of the right cart, AND put the value of the 'after collision velocity' of right cart to the value of the velocity of the left cart." The velocity swap model applies not only in the case of Collision 3, but also in any other case of collision of equal mass carts moving toward each other with any non-zero velocity.

\section{Velocity "fixed" model}

This type of model refers to the case of a model that applies only in a single case of an elastic collision phenomenon, because the way it is constructed does not enable the altering of the values of the velocities of the carts if the user aims to study the same collision phenomenon but with different velocity values. This failure is attributed to the programming code used during constructing the model, since the creators of this model created rules to control the motion of each cart in a different way than the previous models were programmed. Specifically, the rule that is executed in the event of Collision 1 is as follows: "If the left cart's position is adjacent to the position of the right cart, then put zero in the velocity value of the left cart AND put 50 in the velocity of the right cart." The value of " 50 " corresponds to the velocity value of the left moving cart prior to the collision, and thus the velocity value for the right cart is "fixed" by the velocity value of the left cart. Whenever the left cart moves with a constant velocity of 50, then this model operates correctly. But if the left cart moves with a velocity of " 70 ," then the stationary cart will obtain a velocity of "50" (and not "70"). Consequently, this model's applicability is limited to a "fixed" case of an elastic collision and therefore it fails to represent similar collision phenomena. The velocity "fixed" model was also created for the case of Collision 2 (see Table 6), and although the rationale behind its programming was different (the two carts move in opposite directions after their collision), the velocity of each cart after collision was also fixed in an "arbitrary" manner.

\section{Kinetic energy conservation model}

This model was built on the kinetic energy conservation law and appeared in two versions, namely fixed version 1 and fixed version 2 . The creators of either version 
of model stated that since the collision is an elastic one, and given that the kinetic energy of the system of carts is conserved before and after the collision, then the velocity of each cart, according to the kinetic energy conservation law, can be calculated as follows:

$$
\begin{aligned}
& V_{\text {leftafter }}=\sqrt{V_{\text {leftbefore }^{2}}+V_{\text {rightbefore }^{2}}-V_{\text {rightafter }^{2}}}, \\
& V_{\text {rightafter }}=\sqrt{V_{\text {leftbefore }^{2}}+V_{\text {rightbefore }^{2}}-V_{\text {leftafter }^{2}}} .
\end{aligned}
$$

As far as the fixed version 1 model is concerned (applies in Collision 1), besides the motion rules for each cart, the creators created two velocity variables for each cart, one that refers to the before the collision velocity and one that refers to the after the collision velocity, and then created a rule as follows: "If the two carts appear at adjacent boxes, then put zero in $\mathrm{V}_{\text {leftafter." Given that }} \mathrm{V}_{\text {rightbefore }}=0$, then the $V_{\text {rightafter }}=\sqrt{V_{\text {leftbefore }^{2}}}$, and therefore, the right cart will move to the right with a velocity value that is equal to the velocity value of the left cart before the collision.

As far as the fixed version 2 model is concerned (applies in Collision 2), the creators followed a similar programming code as in the case of Collision 1, but the resulting velocities of each cart after the collision were as follows:

$$
V_{\text {rightafter }}=\sqrt{V_{\text {rightbefore }^{2}}} \quad V_{\text {leftafter }}=-\sqrt{V_{\text {leftbefore }^{2}}} .
$$

Although both models were built on the idea of the kinetic energy conservation law, the programming followed for creating each one depended on the case of the collision being modeled, and therefore they were labeled as "fixed" to denote their dependence on the collision they represent.

\section{Momentum conservation model}

This model was built on the idea of the momentum conservation law, although for calculating the value of the velocity of each cart after the collision, the kinetic conservation law was also considered. In doing so, the creators of this model stated that both kinetic energy and momentum are conserved for the system of carts prior to and after the collision, and therefore, the combination of both conservation laws' formulas helps to define the velocity of each cart after their collision. The velocity for each cart after the collision was defined as follows:

$$
\begin{aligned}
V_{\text {leftafter }} & =\frac{\left(m_{1}-m_{2}\right) V_{\text {leftbefore }}+2 m_{2} V_{\text {rightbefore }}}{m_{1}+m_{2}} \\
V_{\text {rightafter }} & =\frac{\left(m_{2}-m_{1}\right) V_{\text {rightbefore }}+2 m 1 V_{\text {leftbefore }}}{m_{1}+m_{2}} .
\end{aligned}
$$

Two different versions of this model were created. The first one, namely "momentum conservation model-simplified with limited applicability," was created 
to represent the case of Collision 1. The creation of this model followed a similar pattern to the "fixed version 1 kinetic conservation model," since the creators formulated a rule for the calculation of the velocities of each cart to eliminate the value of the velocity of the left cart in the event of a collision. Hence, the applicability of this momentum conservation model was limited to the case of Collision 1. On the contrary, the second version of the model (momentum conservation model-advanced and universal applicability) made use of the abovementioned formulas that derived from the combination of the kinetic energy conservation and momentum conservation laws, and therefore, the velocity of each cart after the collision was calculated and set based on each of these formulas. Hence, this model, which was the more advanced one, could be applied to any elastic collision phenomena that occur when bodies of equal or unequal mass and equal or unequal velocities collide.

All of the six abovementioned models point to the diverse ways the participants of the study modeled the five different collision phenomena during Phase 3. According to Table 6, the velocity transfer and the velocity reflect models were created only by the SEdG students and the kinetic energy conservation model was suggested only by the PhG students, whereas the velocity swap, the velocity fixed, and the momentum conservation models were found in both groups of students.

As far as the types of created models progression are concerned, the findings in Table 6 reveal that the models progression of each group differed significantly. Specifically, the majority of SEdG students began (and maintained until collision 4) the creation of their models by placing more emphasis on what happens to the velocities of the carts during the collision and how does this happen (e.g., velocity is transferred from the moving cart to the stationary one or the carts swap their velocities) (see models progression 4, 5, and 6 in Table 6), whereas the majority of $\mathrm{PhG}$ students began (and maintained for all collision cases) the creation of their models by giving priority to conservation laws, either kinetic energy conservation (see model progression 2 in Table 6), or momentum conservation (see model progression 3 in Table 6). In line with this finding, it is noteworthy that although both groups managed eventually to create the momentum conservation model that applies to all five cases of collisions they were studying, the SEdG students delayed the creation of this model until collision 5, whereas the majority of $\mathrm{PhG}$ students developed it from either Collision 1. It is important to state at this point that the SEdG students did not manage to come up with the idea of the momentum conservation law by themselves, given the fact that none of them made use of this law either in the pretest knowledge test or during the study's intervention. Only after they were prompted by the instructors and the curriculum to calculate the product of mass and velocity of each cart in Collision 5 (see Table 1), they managed to "invent" the momentum conservation law and use it for the development of their final models. 


\section{Discussion and implications}

In the current study, we investigated whether the science content knowledge of graduate students (physics vs. science education graduates) affects their modelbased learning during the process of modeling in Stagecast Creator (a graphically represented program language $\mathrm{CPE}$ ). Our findings revealed that a variation in physics knowledge background appears to affect learners' development of modeling competence, at least in a context similar to the one applied in this study. First, we found that the $\mathrm{PhG}$ participants, who entered the study with a strong physics background, constructed the desired models (momentum conservation models) right from the beginning, whereas the SEdG students, who had a weaker physics background, started with simplistic, phenomenological models with not much predictive value and evolved their models, until they have reached the desired models (momentum conservation models), in accordance with their understanding of the phenomenon of collisions. The latter implies that the creation of scientific models requires understanding of the content knowledge involved in the phenomenon under study (i.e., understanding of the components that comprise a phenomenon/system, namely its objects, processes, entities, and interactions; Louca and Zacharia 2014). For instance, in the case of the SEdG students, it was only after they gained a sufficient understanding of the collisions phenomena through the support offered by the instructors and the curriculum materials that the SEdG students managed to create the desired model.

Second, we found the two conditions to vary in terms of development of Metacognitive knowledge about the modeling process and Meta-modeling knowledge (Nature of models and Purpose or utility of models), as well as across all of the modeling practices (Model revision, Models comparison, and Model validation), except the model construction. In particular, the SEdG students were found to have higher mean scores than the $\mathrm{PhG}$ students across all of the aforementioned components of modeling competence. This appears to indicate that modeling competence developed better among students with weaker science content background than among students with stronger science background. These findings point to significant differences between students with strong and weak science background when enacting modeling. It is important to note that we used a test which measured the components of modeling competence in science subject domain contexts different from the one of the study. The latter implies that students' modeling competence appears not to be content/(collision)-dependent. Confirmation of this finding through further research would have important practical implications about how modeling-based learning should be implemented.

In order to shed light on the reasons behind these differentiations, we looked at the models that the students constructed to examine how the process of modeling evolved/progressed in the two conditions. In the case of the SEdG condition, the students were found to construct more models (three to four models) to represent each of the five different but related collision phenomena during the study's intervention than the PhG students, who were found to follow a completely different model progression. In particular, the PhG students were found to create one or two 
models throughout the study. By comparing these two different model progressions, it becomes apparent that they differed in the variability and the nature of the underlying mechanisms of their models. Specifically, the majority of the SEdG students began with the construction of the velocity transfer model, then moved to the velocity reflect model, next to the velocity swap model and finally, after receiving substantial scaffolding from the instructors and the curriculum (i.e., they were prompted to calculate the product of mass and velocity of each cart in Collision 5, then calculate the sum of the products prior to and after collision, and after concluding that the sums are equivalent, they were introduced to the momentum conservation law), came up with the momentum conservation model. On the contrary, the majority of the PhG students began directly with the momentum conservation model and maintained this model for the whole sequence of collision phenomena, since it correctly applied to each new collision case.

When looking into the underlying mechanisms of the SEdG condition models it becomes obvious that the SEdG students were constructing phenomenological models. Phenomenological models are models that only represent the observable properties of the phenomenon and refrain from including the actual underlying mechanism; if one is included, it is just for showing how the phenomenon behaves in that particular case and does not necessarily apply to other collision cases (Louca and Zacharia 2008). Specifically, the mechanisms of the SEdG students' models that were built for collisions with equal mass carts, focused on the idea that during the collision of the carts their velocity is either "transferred" (Collision 1) or "reflected" (collision 2) or "swapped" (collision 3 and 4), because these students focused only on representing the phenomenon as observed in each particular case, without worrying whether the mechanism of their model would be applicable for other collision cases (which is an essential aspect for modeling competence). It was the succession of different collision classes that enabled them to understand that they had to "invent" a mechanism that could be applied across 1-D elastic collisions, namely the mechanism of the momentum conservation model. Predictive and interpretive potential is one of the epistemic criteria that distinguishes a scientific model from other forms of representations or artifacts that are created or used in science (Giere 1999; Nersessian 1999; Pluta et al. 2011; Schauble et al. 1991; Schwarz et al. 2009). Obviously, the idea of predictive and interpretive potential is something that did not exist among the SEdG students at the beginning, but was developed over time, due to the need to address more and more classes of collisions. In the case of the PhG students, it is not apparent if this potential was there or they just focused on applying the momentum conservation model per se.

Needless to say, all the other invented mechanisms before the "invention" of the mechanism of the momentum conservation model were inconsistent with extant physics knowledge, namely the conservation of momentum theory. However, the fact that they were inconsistent with the conservation of momentum theory does not mean that the development of these mechanisms did not have any added value modeling-wise (assuming that they were consistent with the data and observations collected from the specific collisions they were associated with). In other words, this finding implies that the SEdG students' lack of physics background knowledge in the context of 1-D elastic collisions did not impede or frame their thinking and 
modeling perspective while trying to come up with a mechanism to explain how the observed collision phenomena occurred the way they did and then to integrate it in their model. In fact, the model progression they followed reveals a progression from naive conceptions of a model and its underlying mechanism to a sophisticated understanding of models as explanatory tools, which help in thinking theoretically or guiding the generation of new knowledge (Windschitl and Thompson 2006). The latter was also confirmed from the data analysis of the modeling competence posttest, particularly from the fact that the SEdG students were found to have higher mean scores on the Meta-modeling knowledge (Nature of models and Purpose or utility of models) component of the test. Consequently, SEdG students' personal engagement in developing the abovementioned models and progressing from one model to the other, whenever their model failed to explain a new case of collision, could have enabled them to appreciate "interpretation" as a major aspect of the nature of models. They came to understand, for instance, that when constructing a model one should seek to explain how and why a phenomenon occurs and not what happens when (Bamberger and Davis 2013; Penner et al. 1997).

On the other hand, the majority of the PhG students focused on the momentum conservation model right from the beginning because they already knew from their physics background about the conservation of the momentum theory (i.e., both kinetic energy and momentum of a closed system of colliding bodies are conserved). Their strong science background was the driving force behind their process of modeling, rather than representing a phenomenon phenomenologically as did the SEdG students. This enabled them to stay focused only on the momentum conservation model throughout the study and thus be more efficient in terms of identifying the correct underlying mechanism of their model than the SEdG students. Apparently, their strong physics background framed their model construction, especially its underlying mechanism. This means that the $\mathrm{PhG}$ students began and maintained the construction of their models with the aim of either applying or confirming their physics knowledge in the studied collisions, without examining other alternatives that might help them to formulate models in a simplified manner. Other researchers have argued that modeling-based learning is usually more productive for students, when they start with simpler models (Hogan and Thomas 2001).

The fact that the PhG students did not get a chance to work through different models until they reached the scientifically correct one, had negative implications for their personal epistemologies of scientific knowledge and epistemic understanding with respect to the nature and purpose of models and modeling, in particular. This also explains why $\mathrm{PhG}$ students scored significantly lower scores than the SEdG students on the Meta-modeling knowledge (Nature of models and Purpose or utility of models) component of the modeling competence test. A close look at their responses to the test items on Meta-modeling knowledge shows that the way $\mathrm{PhG}$ students enacted modeling left them with two important epistemic (mis)understandings. First, scientific knowledge is well-established knowledge that neither can be denied nor should be tested against new data from a phenomenon. This misunderstanding indicates that $\mathrm{PhG}$ students, even though they studied core ideas and principles about several physics domains for four years during their 
undergraduate studies, did not become aware that “...complex theories in science are developed through a process of successive elaboration and refinement in which scientific models are created and modified to account for new phenomena that are uncovered in exploring a domain" (White and Frederiksen 1998, p. 7). The following statement made by $\mathrm{PhG}$ student \#33 when the instructor prompted him and his partner to think of an alternative mechanism that could be used to explain what happens during collision 2, is particularly revealing:

I cannot think of an alternative way to show how this collision occurred, since my physics knowledge tells me that during the collision of the carts the kinetic energy and their momentum are conserved. Since these laws apply in every elastic collision phenomena, then we need to build our models around this idea.

The second misunderstanding entails that models and the process of modeling are used to confirm or verify what is known and not as a means to develop scientific knowledge. This emergent view signifies that the PhG students might have failed to progress from the naive conception of models as final form devices that are created or used for confirming previously established knowledge (Crawford and Cullin 2004) to a sophisticated understanding of models as explanatory tools that help in thinking theoretically or guiding the generation of new knowledge (Pluta et al. 2011; Windschitl and Thompson 2006). The following statement made by $\mathrm{PhG}$ student \#14 when the instructor asked why the idea of "velocity swap" cannot be used in the case of collision 3 , is particularly revealing:

I need to declare that during the collision the two carts swap their kinetic energy and not their velocities. Even though we started building our model around the idea of velocity swap, in improving our model we will make it more scientific by showing the kinetic energy conservation. This is a fundamental knowledge that I already know and need to incorporate it in our model.

As far as the differences in students' modeling practices and metacognitive knowledge are concerned, these might be attributed to the different modeling approaches and perspectives evidenced in their models creation progressions, and the models created per se. In terms of their modeling practices, the fact that the PhG students created a very limited number of models to represent the five different cases of the collision phenomena, albeit consistent with the extant physics knowledge, might have influenced the development of their model revision, model comparison, and model validation practices, because the limited number of models they created did not serve as a platform to gain rich experiences of revising, comparing, and validating their models. The SEdG students, on the contrary, were engaged in multiple cycles of model formulation, revision, comparison, and validation because of the variety of the models created for representing the different classes of collisions. More specifically, evidence from the posttest responses of the SEdG students indicates that this group of students developed more sophisticated and epistemically compatible criteria (Pluta et al. 2011) when asked to evaluate, compare, or validate certain models in different contexts. 
Likewise, PhG students' moderate development of metacognitive knowledge about the modeling process can also be attributed in the limited number and types of models they created, which in turn resulted in a limited number of iterations of the modeling cycle they completed. Given that their modeling practice resembled more a linear and not an iterative approach, it might have served to inhibit the development of their epistemic awareness with respect to models and metacognitive knowledge about the modeling process, as they did not come to understand that "models can be evaluated and refined through an iterative cycle of comparing their predictions with the real world and then adjusting them, thereby potentially yielding insights into the phenomenon being modeled" (NRC 2012, p. 57).

The findings of the present study have implications in two directions. Firstly, given the restriction that students' prior content knowledge imposed on their modeling process and the types of models that were created, science education instructors might need to think of and carefully select the context of future modeling-based interventions so that participants' prior content knowledge will not interfere with the context of the instruction. This will provide participants with an open space to think more creatively and "out of the box," as their perspective on modeling would not be framed by their prior knowledge, as it was the case for the SEdG students. It is anticipated that an unfamiliar science domain will challenge students to focus on various alternative interpretations to explain their observations of how a particular phenomenon functions, rather than seeking to confirm their prior knowledge through integrating it in their models. In this study, it was found that the students who were engaged in multiple and iterative cycles of formulating, testing, revising, comparing, and validating models for a particular phenomenon, namely the SEdG students who were involved in an unfamiliar science domain, developed more robust modeling practices, metacognitive knowledge about the modeling process, and came to appreciate models as epistemic constructs for representing, interpreting, and predicting of phenomena, than the $\mathrm{PhG}$ students who were familiar with the science domain. One reasonable conjecture coming out of this study is that the selection of the phenomenon to be modeled must be unfamiliar to the students, if we want them to follow an authentic process of modeling, similar to the one usually followed by scientists. Given the impact that such a claim might have on practicing modeling-based learning, we suggest that this issue is prioritized by fellow researchers of the domain and be included/examined in their future research studies.

Secondly, given our participants' different science content background and considering the challenging and demanding task of modeling both from the perspective of the learner and the perspective of the course designer and instructor, it is suggested that a more well-structured modeling-based learning curriculum should be followed if we want them to practice modeling as scientists do. The rather open-ended modeling-based learning curriculum followed in this study allowed students to follow different modeling paths, which resulted in non-uniform development of modeling competence among participants, regardless of their science background. It could be that a well-structured modeling-based learning curriculum could have enabled students to follow similar modeling paths. A more explicit focus on the development of each aspect of learners' modeling practice, as well as the integration of epistemic-oriented scaffolds and prompts for reflection 
about the nature and purpose of scientific models during constructing, revising, and evaluating their own models might have served as catalysts for the development of all aspects of modeling competence in unison. The latter suggestion is in line with the recommendations made by Schwarz and White (2005), who argued that engaging students in simply developing models is not enough to develop epistemological awareness toward models and modeling, but "one needs to add a 'meta-modeling layer' to a modeling curriculum, which enables students to develop not only scientific models but also explicit theories about the nature of models themselves" (p. 167).

Finally, it should be noted that the study carries a number of limitations, such as the small sample size, as well as the fact that the data were collected only from the 1-D collisions subject matter domain. These limitations point to the need of further research in the modeling-based learning domain in order to get a complete picture of how science content background affects students' development of modeling competence.

\section{Appendices}

\section{Appendix 1}

See Table 7.

Table 7 A sample item of the knowledge test

\section{Knowledge Test Item 3}

The spheres below are located on a frictionless table (top view). Both spheres have equal mass and roll with a constant velocity following the direction of the arrows.

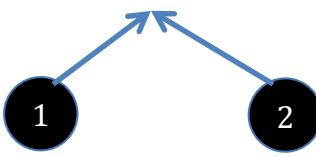

1. Draw the direction each sphere rolls after their collision.

2. Calculate the velocity of each sphere after the collision.

3. Explain your drawing and the reasoning behind the calculation of the velocity of each sphere. 


\section{Appendix 2}

\section{See Table 8.}

Table 8 Sample of items of the modeling competence test

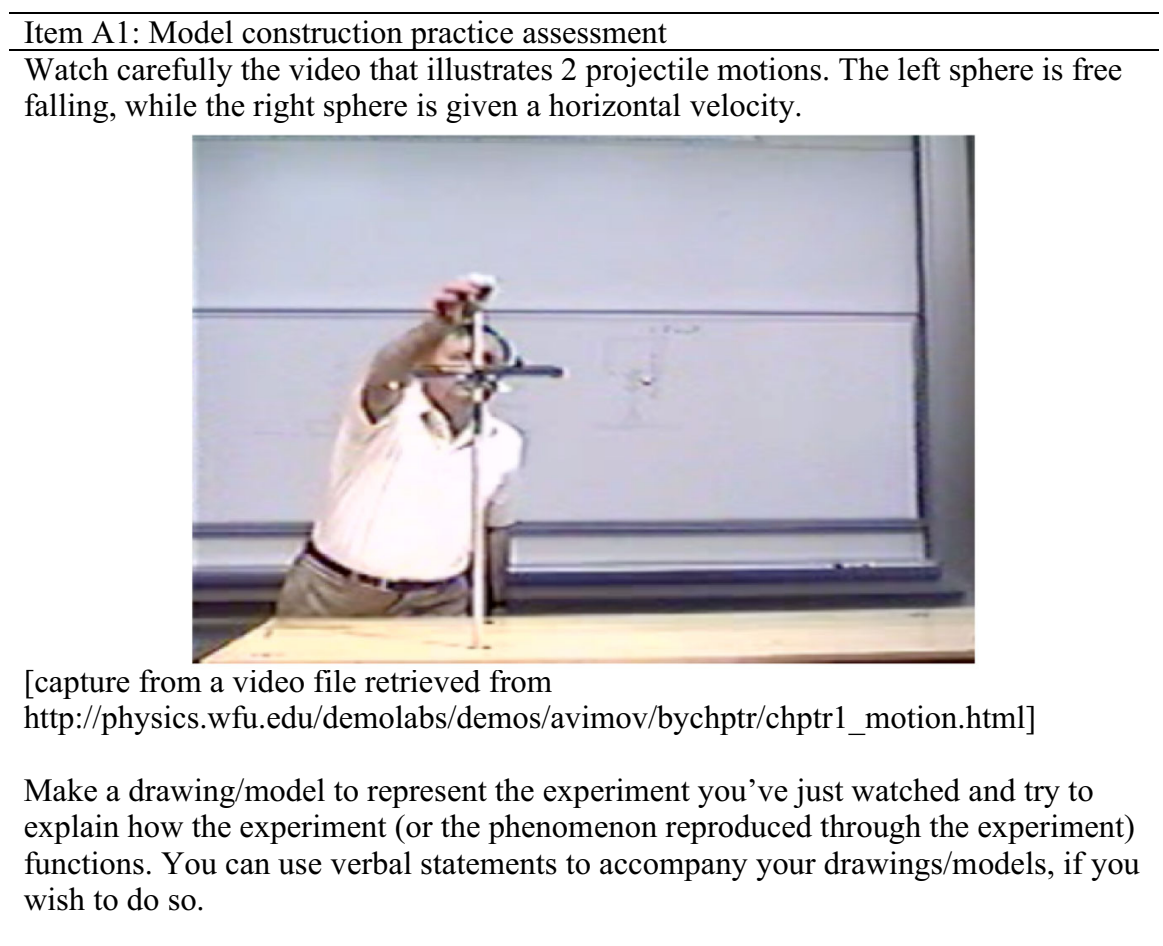

\begin{tabular}{l} 
Item E2: Metacognitive knowledge about the modeling process \\
Jim would like to create a model to represent the growth of a bean seed. However, he does \\
not know the steps that need to be followed for modeling this process. Can you help him? \\
Describe below the steps that Jim should follow in order to create the model. \\
\hline \\
\hline \\
\hline
\end{tabular} 
Table 8 continued

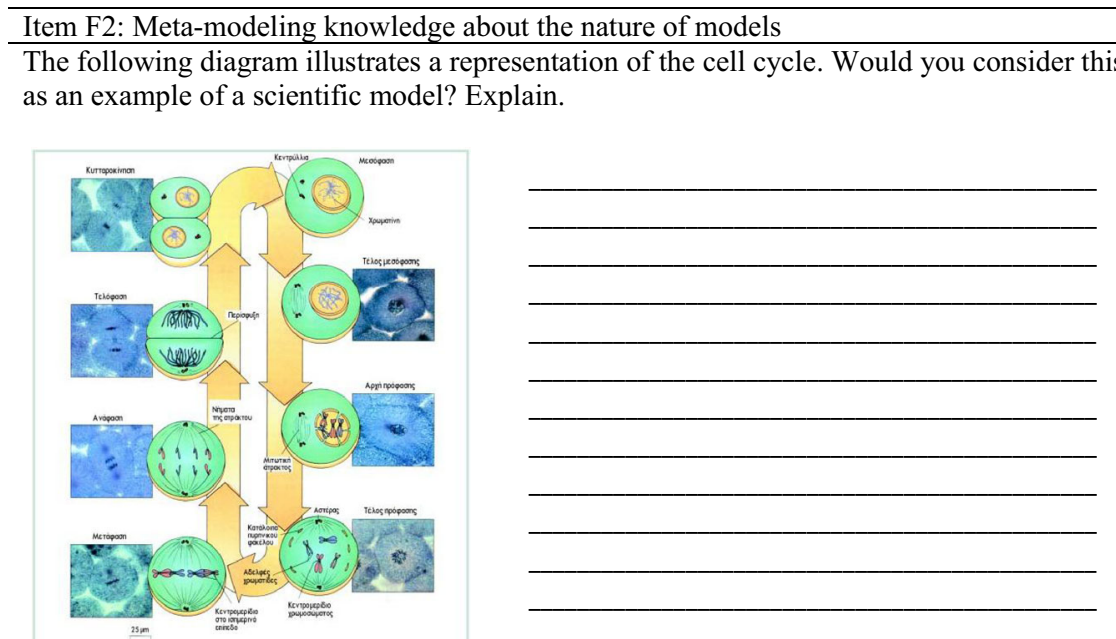

\section{Appendix 3}

\section{See Table 9.}

Table 9 The scoring rubric for the meta-modeling knowledge item F2 about the nature of models

\begin{tabular}{lll}
\hline Correct answer $^{\mathrm{a}}$ (score) & $\begin{array}{l}\text { Expected explanation } \\
\text { (score) (total score) }\end{array}$ & $\begin{array}{l}\text { Example of a participant's response } \\
\text { (total score, condition, participant } \\
\text { number) }\end{array}$
\end{tabular}

Yes, the illustration can be considered as a case of a scientific model (1)
The illustration entails the three major aspects that a scientific model should entail. These are as follows:

i. Representational complexity (e.g., the model describes and represents a phenomenon) (1)

ii. Interpretive potential (e.g., the model provides a possible mechanism of how the phenomenon functions) (1)

iii. Predictive power (e.g., the model can be used to test predictions about specific aspects of the phenomenon) (1) [3]
"A representation can be considered as a scientific model, if it fulfills three criteria: a scientific model should: (a) represent in an acceptable way the phenomenon (1); (b) provide strong explanatory power (1); and (c) enable the formulation of hypotheses and testing of predictions (1). This model satisfies these criteria in some way (1). Firstly, it represents in an adequate way the cell cycle because it shows all stages of the cell cycle ( $1^{\text {st }}$ criterion). Secondly, one can explain the various phases of the cell cycle because the pictures that are provided entail the mechanism that controls the cell division (2nd criterion). Thirdly, by studying this model one is able to predict what is going to happen in any phase of the cell cycle (e.g., we can 
Table 9 continued

\begin{tabular}{lll}
\hline Correct answer $^{\mathrm{a}}$ (score) & $\begin{array}{l}\text { Expected explanation } \\
\text { (score) (total score) }\end{array}$ & $\begin{array}{l}\text { Example of a participant's response } \\
\text { (total score, condition, participant } \\
\text { number) }\end{array}$ \\
\hline & $\begin{array}{l}\text { predict what is going to happen during } \\
\text { the teloPhase 1nd then use the model to } \\
\text { test if our prediction was correct) }\left(3^{\text {rd }}\right. \\
\text { criterion)." [4, SEdG \#12] }\end{array}$ \\
\hline
\end{tabular}

\section{References}

Bamberger, Y. M., \& Davis, E. A. (2013). Middle-school science students' scientific modelling performances across content areas and within a learning progression. International Journal of Science Education, 35(2), 213-238.

Barab, S., Hay, K., Barnett, M., \& Squire, K. (2001). Constructing virtual worlds: Tracing the historical development of learner practices. Cognition \& Instruction, 19(1), 47-94.

Crawford, B. A., \& Cullin, M. J. (2004). Supporting prospective teachers' conceptions of modelling in science. International Journal of Science Education, 26(11), 1379-1401.

Duschl, R., \& Grandy, R. (2008). Reconsidering the character and role of inquiry in school science: Framing the debates. In R. Duschl \& R. Grandy (Eds.), Teaching scientific inquiry: Recommendations for research and application (pp. 1-37). Rotterdam/Taipei: Sense Publishers.

Duschl, R. A., Schweingruber, H. A., \& Shouse, A. W. (Eds.). (2007). Taking science to school: Learning and teaching science in grades $K-8$. Washington, DC: National Academies Press.

Fretz, E. B., Wu, H. K., Zhang, B., Davis, E. A., Krajcik, J. S., \& Soloway, E. (2002). An investigation of software scaffolds supporting modeling practices. Research in Science Education, 32(4), 567-589.

Giere, R. N. (1999). Using models to represent reality. In L. Magnani, N. J. Nersessian, \& P. Thagard (Eds.), Model-based reasoning in scientific discovery (pp. 41-57). New York: Kluwer Academic and Plenum.

Halloun, I. (1996). Schematic modeling for meaningful learning of physics. Journal of Research in Science Teaching, 33(9), 1019-1041.

Heck, A., Kędzierska, E., \& Ellermeijer, T. (2009). Design and implementation of an integrated computer working environment. Journal of Computers of Mathematics and Science Teaching, 28(2), 147-161.

Hestenes, D. (1987). Toward a modeling theory of physics instruction. American Journal of Physics, 55(5), 440-454.

Hestenes, D. (1992). Modeling games in the Newtonian world. American Journal of Physics, 60(8), $732-748$.

Hestenes, D. (2010). Modeling theory for math and science education. In R. Lesh, C. R. Haines, P. L. Galbraith, \& A. Hurford (Eds.), Modeling Students' Mathematical Modeling Competencies (pp. 13-41). US: Springer.

Hogan, K., \& Thomas, D. (2001). Cognitive comparisons of students' systems modeling in ecology. Journal of Science Education and Technology, 10(4), 319-345.

Kafai, Y. B., \& Resnick, M. (Eds.). (1996). Constructionism in practice: Designing, thinking, and learning in a digital world. Mawhaw, NJ: Lawrence Erlbaum Associates.

Lehrer, R., Horvath, J., \& Schauble, L. (1994). Developing model-based reasoning. Interactive Learning Environments, 4, 219-231.

Louca, T. L., \& Zacharia, C. Z. (2008). The use of computer-based programming environments as computer modeling tools in early science education: the cases of textual and graphical program languages. International Journal of Science Education, 30(3), 1-37.

Louca, L., \& Zacharia, Z. C. (2012). Modeling-based learning in science education: A review. Educational Review, 64(1), 471-492. 
Louca, L., \& Zacharia, Z. C. (2014). Examining learning through modeling in K-6 science education. Journal of Science Education and Technology,. doi:10.1007/s10956-014-9533-5.

Louca, L., Zacharia, Z. C., Michael, M., \& Constantinou, C. (2011). Objects, entities, behaviors and interactions: A typology of student-constructed computer-based models of physical phenomena. Journal of Educational Computing Research, 44(2), 173-203.

Louca, L., Zacharia, Z. C., \& Constantinou, C. (2012). In quest of productive modeling-based learning discourse in elementary school science. Journal of Research in Science Teaching, 48(8), 919-951.

National Research Council. (2012). A framework for K-12 science education: practices, crosscutting concepts, and core ideas. Committee on a conceptual framework for new K-12 science education standards. Board on science education, division of behavioral and social sciences and education. Washington, DC: The National Academies Press.

Nersessian, N. (1992). How do scientists think? Capturing the dynamics of conceptual change in Science. Cognitive Models of Science, 15, 3-44.

Nersessian, N. J. (1999). Model-based reasoning in conceptual change. In L. Magnani, N. J. Nersessian, \& P. Thagard (Eds.), Model-based reasoning in scientific discovery. New York: Kluwer Academic/ Plenum Publishers.

Oh, P. S., \& Oh, S. J. (2010). What teachers of science need to know about models: an overview. International Journal of Science Education, 32, 1-22.

Papaevripidou, M., Constantinou, C. P., \& Zacharia, Z. C. (2007). Modeling complex marine ecosystems: Using Stagecast Creator to foster fifth graders' development of modeling skills. Journal of Computer Assisted learning, 23(2), 145-157.

Papert, S. (1980). Mindstorms: Children, computers and powerful ideas. New York, NY: Basic Books, Inc., Publishers.

Papert, S. (1993). The children's machine: Rethinking school in the age of the computer. NY: Basic Books.

Pata, K., \& Sarapuu, T. (2006). A comparison of reasoning processes in a collaborative modelling environment: Learning about genetics problems using virtual chat. International Journal of Science Education, 28, 1341-1368.

Penner, D. E. (2001). Cognition, computers, and synthetic science: Building knowledge and meaning through modeling. Review of Research in Education, 25, 1-36.

Penner, D. E., Giles, N. D., Lehrer, R., \& Schauble, L. (1997). Building functional models: Designing an elbow. Journal of Research in Science Teaching, 34, 125-143.

Pluta, W. J., Chinn, C. A., \& Duncan, R. G. (2011). Learners' epistemic criteria for good scientific models. Journal of Research in Science Teaching, 48(5), 486-511.

Schauble, L., Glaser, R., Raghavan, K., \& Reiner, M. (1991). Causal models and experimentation strategies in scientific reasoning. The Journal of the Learning Sciences, 1(2), 201-238.

Schwarz, C. V., \& Gwekwerere, Y. V. (2006). Using a guided inquiry and modeling instructional framework (EIMA) to support preservice K-8 science teaching. Science Education, 91, 1-29.

Schwarz, C. V., \& White, B. Y. (2005). Metamodeling knowledge: developing students' understanding of scientific modeling. Cognition and Instruction, 23, 165-205.

Schwarz, C. V., Reiser, B. J., Davis, E. A., Kenyon, L., Acher, A., Fortus, D., et al. (2009). Developing a learning progression for scientific modeling: Making scientific modeling accessible and meaningful for learners. Journal of Research in Science Teaching, 46, 632-654.

Sherin, B. (2001). A comparison of programming languages and algebraic notation as expressive languages for physics. International Journal of Computers for Mathematical Learning, 6, 1-61.

Sherin, B., diSessa, A. A., \& Hammer, D. (1993). Dynaturtle revisited: Learning physics through collaborative design of a computer model. Interactive Learning Environments, 3(2), 91-118.

Singh, G., \& Chignell, M. H. (1992). Components of the visual computer. The Visual Computer, 9 , $115-142$.

Sins, P. H. M., Savelsbergh, E. R., \& van Joolingen, W. R. (2005). The difficult process of scientific modelling: An analysis of novices' reasoning during computer-based modelling. International Journal of Science Education, 27(14), 1695-1721.

Smith, D. C., \& Cypher, A. (1999). Making programming easier for children. In A. Druin (Ed.), The design of children's technology. San Francisco: Morgan Kaufmann Publishers Inc.

Smith, D. C., Cypher, A., \& Telser, L. (2000). Novice programming comes of Age. Communications of the ACM, 43, 75-81. 
Snir, J., Smith, C. L., \& Raz, G. (2003). Linking phenomena with competing underlying models: A software tool for introducing students to the particulate model of matter. Science Education, 87, 794-830.

Strauss, A., \& Corbin, J. (1990). Basics of qualitative research: Grounded theory procedures and techniques. Newbury Park, CA: Sage Publications.

White, B. Y., \& Frederiksen, J. R. (1998). Inquiry, modeling and metacognition: Making science accessible to all students. Cognition and Instruction, 16, 3-118.

Windschitl, M., \& Thompson, J. (2006). Transcending simple forms of school science investigation: The impact of pre-service instruction on teachers' understandings of model-based inquiry. American Educational Research Journal, 43(4), 783-835.

Windschitl, M., Thompson, J., \& Braaten, M. (2008). Beyond the scientific method: model-based inquiry as a new paradigm of preference for school science investigations. Science Education, 92, 1-27.

Marios Papaevripidou is a Specialist Teaching Fellow of Science Education at the University of Cyprus and Senior Researcher of the Research in Science and Technology Education Group at the University of Cyprus. He completed a B.A in Education, an M.A in Learning in Natural Sciences, and a Ph.D. in Learning in Natural Sciences at the University of Cyprus. His research interests entail the use of modeling as both a learning tool and an instructional approach in science teaching and learning, and also the design and research validation of computer-supported curriculum materials to foster teachers' professional development in modeling-centered scientific inquiry. He participated in several research projects that focused on enhancing students' competence in science through modeling- and inquiry-based activities and preparing teachers to enact science teaching through modeling-centered scientific inquiry with the use of technology.

Zacharias C. Zacharia is an Associate Professor of Science Education and Director of the Research in Science and Technology Education Group at the University of Cyprus. He completed a B.A. in Education at the University of Cyprus (Cyprus), a B.A. in Physics at Rutgers University-New Brunswick (USA), and his graduate studies (M.A., M.Sc., M.Phil and Ph.D.) in Science Education at Columbia University, New York (USA). He was the (co-) coordinator of several research projects concerning computer supported inquiry learning and inquiry-based laboratory experimentation that received continuous financial support over the years from the Cyprus Research Promotion Foundation and the European Commission. His research interests include the development and assessment of inquiry-based science curriculum and computer supported inquiry learning environments. Zacharias Zacharia has received several awards in recognition of outstanding scholastic achievement and excellence, and has published many papers in major ISI journals. 